\title{
Synthesis and thermal properties of new copolyesters based on polycaprolactone
}

\author{
El Miloud Maafi, ${ }^{1}$ Fouad Malek, ${ }^{1 *}$ Lan Tighzert, ${ }^{2}$ Fouad Laoutid, ${ }^{3}$ Philippe Dubois ${ }^{3}$
}

${ }^{1 *}$ Laboratoire de Chimie Organique, Macromoléculaire et Produits Naturels, URAC 25

- Faculté des Sciences - Université Mohamed Premier. Bd Mohamed VI, BP: 717 60000 Oujda - Morocco; fax : 00212536500603 ; e-mail: malek_fso@yahoo.fr

${ }^{2}$ Groupe de Recherche En Sciences Pour l'Ingénieur / Matériaux Fonctionnels (GRESPI / MF - EA 4301) - Ecole Supérieure d'Ingénieurs en Emballage et Conditionnement (ESIEC), Esplanade Roland Garros - Pôle Henri-Farman, B.P.1029 - 51686 Reims Cedex 2, France. Fax: 333269137 64; e-mail : lan.tighzert@univreims.fr

${ }^{3}$ Center of Innovation and Research in Materials \& Polymers (CIRMAP), Laboratory of Polymeric and Composite Materials (LPCM), University of Mons \& Materia Nova Research Center, Place du Parc 20, 7000 Mons, Belgium; fax : 3265373484 ; email : philippe.dubois@umons.ac.be

(Received: 19 May, 2011; published: 14 March, 2012)

\begin{abstract}
Several copolyesters were synthesized from carboxytelechelic poly $(\varepsilon-$ caprolactone) and bis(2-hydroxyethyl)terephthalate (BHET), using a two-step method and a one-step method providing regular and random distributions of starting comonomers in the copolyester chains, respectively. Even with an identical molar comonomer composition, the properties of obtained copolyesters depended on the synthesis method, therefore the comonomer distribution along the polymer chain. The copolyester structure was characterized by ${ }^{1} \mathrm{H}$ and ${ }^{13} \mathrm{C}$ NMR and FTIR spectroscopy. The thermal properties of synthesized copolyesters were also studied by DSC and TGA demonstrating the influence of aromatic rings spread along the macromolecular polyester chain.

Keywords : polyester, polycaprolactone, polycondensation, thermal properties.
\end{abstract}

\section{Introduction}

Presently, increasing volumes of plastics are manufactured and used for various applications because of their versatility and ability to be mass-produced. However, they are usually not naturally decomposed, thus they are considered to cause some environmental problems. For this reason, many scientists have worked to develop new biodegradable polymers. A number of biodegradable polyesters have been developed, and some of them are commercially available (e.g., poly $(\beta$ hydroxybutyrate) (PHB), poly( $\varepsilon$-caprolactone) (PCL), polybutylene succinate (PBS), polylactide $(P L A), \ldots)$. All these polyesters are based exclusively on aliphatic monomers. Although these aliphatic polyesters are applicable for various purposes, they exhibit some disadvantages. The polymer characteristics are either unsuitable for certain applications or insufficiently adaptable to specific product requirements, for instance, the melting point of PCL is relatively low, about $60{ }^{\circ} \mathrm{C}$ [1-4]. In contrast, pure aromatic polyesters, such as polyethyleneterephthalate (PET), which are 
produced on a large industrial scale, display satisfactory properties, but are resistant to microbial attack [5-9].

According to the literature [10-20], the introduction of terephthalic units in the structure of polyester improves its physical properties. Tokiwa and Suzuki [12, 13] indicated that the physical properties of aliphatic polyesters are improved by adding aromatic (poly)esters into the polymer chains. They also suggested that the biodegradation rate of copolyesters made from aliphatic and aromatic polyesters can be regulated by controlling the composition in aromatic segments. Copolyesters, particularly those obtained from 1.4-butanediol, adipic acid and terephthalic acid (PBAT copolyesters), look promising as biodegradable materials in packaging and other applications.

Indeed, PBAT is now marketed under the trade name of Ecoflex ${ }^{\circledR}$. Witt et al $[19,20]$ showed that this copolyester display good mechanical and thermal properties when the molar concentration of terephthalic acid is superior to $25 \%$, but its rate of biodegradation declines sharply at a concentration higher than $50 \%$. Therefore, the ratio of aliphatic and aromatic comonomers must be chosen judiciously. For a terephthalic acid molar concentration between 25 and $50 \%$ in maximum, the copolyesters reach a good compromise between biodegradability and properties of use.

Bis(2-hydroxyethylene) terephthalate (BHET) is a commercial low molecular weight diol based on one terephthalic unit and can be used in the development of polyester materials. Recently, some of us have used BHET to synthesize polyurethanes based on PCL, the obtained polymers possess good thermal and mechanical properties [21- 23].

In this study, it is aimed to tune the thermal performance of PCL by synthesizing polycondensates containing in their structure ester links and aromatic rigid segments in limited quantities in order to preserve their biodegradability. We report the syntheses of two types of polycondensates : i) so-called "regular" polyesters elaborated by direct polycondensation of carboxytelechelic PCL with BHET and ii) "random" polyesters by polycondensation of alkoxytelechelic PCL/BHET and succinic anhydride in selected relative quantity. The carboxytelechelic PCL is first synthesized by esterification reaction between commercially available $\alpha, \omega-\mathrm{OH}$ oligo-PCL and succinic anhydride. These conditions enabled us to obtain various polyesters with different structures and thermal properties.

\section{Results and discussions}

\section{Syntheses of PCL-based copolyesters}

\section{-Synthesis of carboxytelechelic PCL oligomers}

Firstly, $\alpha, \omega-\mathrm{OH}$ oligo-PCL reacted with succinic anhydride giving carboxytelechelic PCL oligomers which are not commercially available. Secondly, the copolyesters were obtained by reaction between the obtained carboxytelechelic PCL and BHET (Scheme 1).

In order to control this reaction when using the PCL of molar mass $2000 \mathrm{~g}_{\mathrm{mol}}{ }^{-1}$, the reaction was first studied with $\mathrm{PCL}$ oligomers of lower molar mass $\left(530 \mathrm{~g} \cdot \mathrm{mol}^{-1}\right)$ used as model. The analyses of the purified product by FTIR and ${ }^{1} \mathrm{H}$ NMR show that the 
ring opening reaction of succinic anhydride occurred effectively. The mass yield of reaction was $80 \%$.

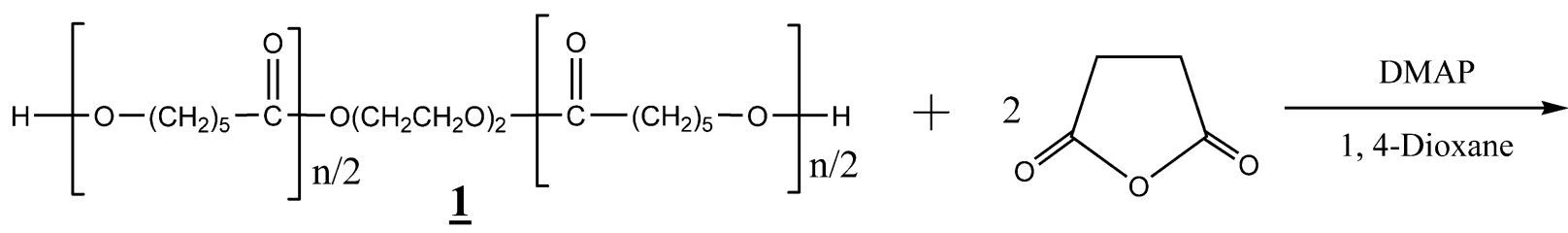

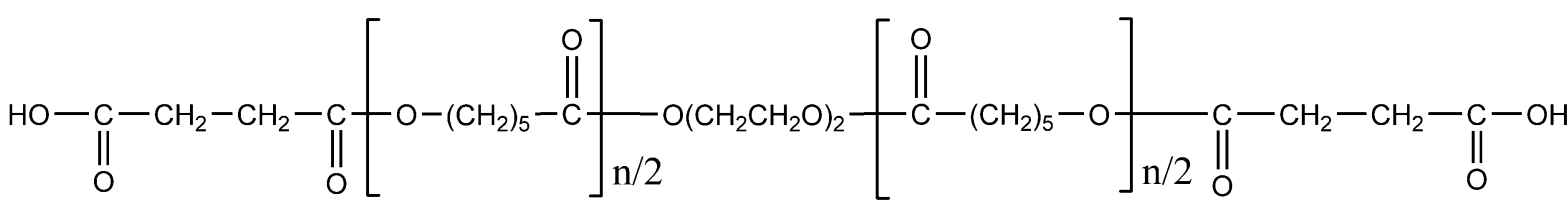

Scheme 1. Synthesis of carboxytelechelic poly ( $\varepsilon$-caprolactone) oligomers.

In the ${ }^{1} \mathrm{H}$ NMR spectrum (Figure 1), we note the presence of a broad signal at 8.4 ppm corresponding to the acid proton. The $\alpha$ - and $\beta$-protons of the acid function appear as a multiplet centred at $2.55 \mathrm{ppm}$. Other peaks correspond to the protons of the aliphatic chain of PCL. The ratio of the peak integration of different signals attests for quantitative esterification reaction between succinic anhydride and PCL diol.

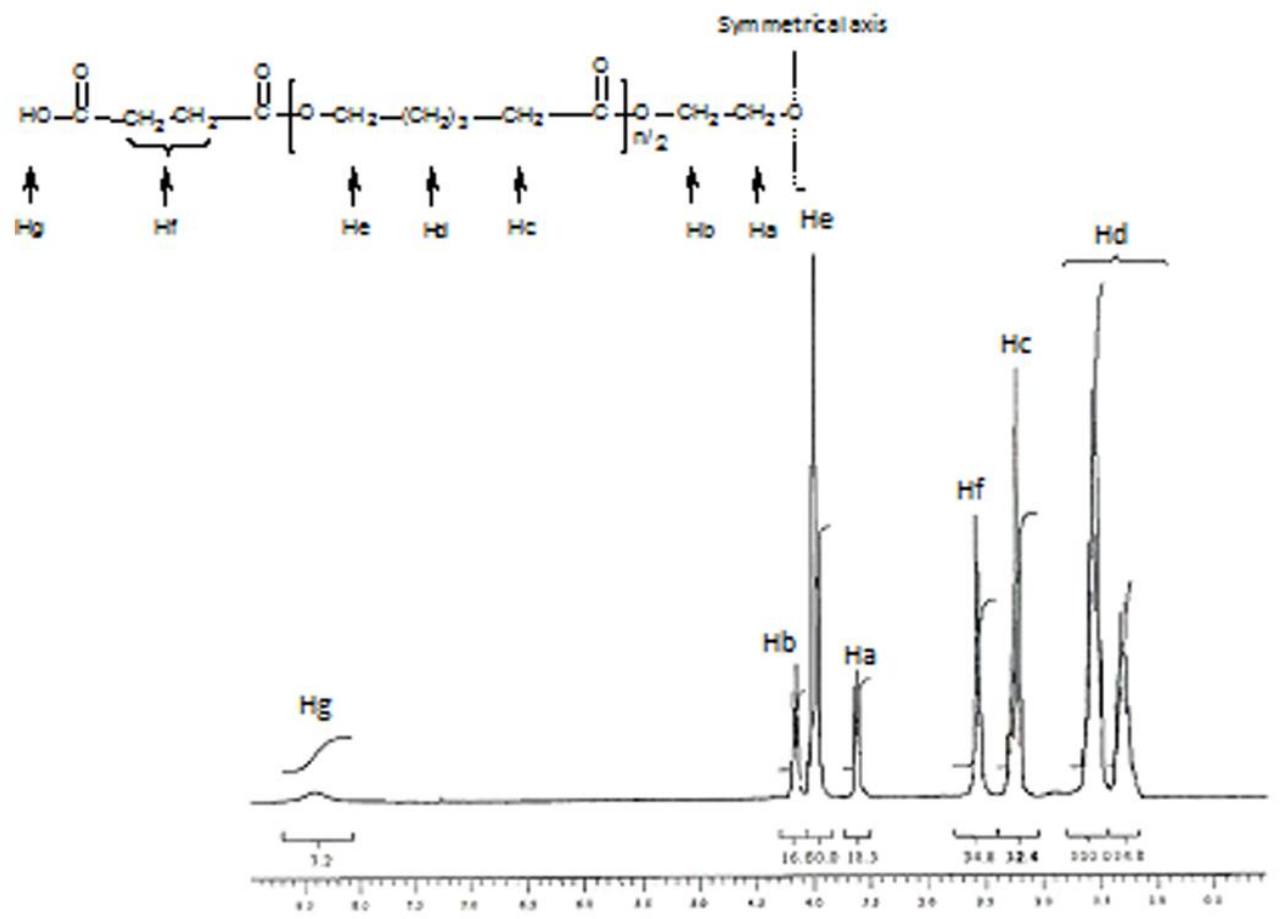

Fig. 1. ${ }^{1} \mathrm{H} \mathrm{NMR}\left(250 \mathrm{MHz}, \mathrm{CDCl}_{3}\right)$ spectrum of carboxytelechelic poly( $\varepsilon$-caprolactone).

We repeated the same reactions with $\alpha, \omega-\mathrm{PCL}$ diol of higher molar mass, i.e., 2000 g.mol ${ }^{-1}$. The analyses of the purified product by ${ }^{1} \mathrm{H}$ NMR and FTIR show that the 
reaction took place. We obtained spectra identical to the preceding ones with the same signals at the same chemical shifts.

The comparison of size exclusion chromatograms (SEC) -before and after esterification reaction- shows a slight increase in molar mass, but the obtained product displays the same polydispersity index as that of the starting product and shows no formation of by-products. The molar mass of PCL diol measured by SEC is close to the value announced by the supplier $\left(2100 \mathrm{~g} \cdot \mathrm{mol}^{-1}\right.$ instead of $2000 \mathrm{~g} \cdot \mathrm{mol}^{-1}$ ) with a dispersity index of 1.47. After reaction, the obtained carboxytelechelic PCL oligomers have a molar mass of $2360 \mathrm{~g} \cdot \mathrm{mol}^{-1}$ and a dispersity index of 1.45.

According to the recorded results, we can conclude that the reactivity of terminal $\mathrm{OH}$ functions of $\alpha, \omega-\mathrm{OH} P C L$ is independent of its length (at least within the range of investigated molecular weigth) and the ring opening reaction of succinic anhydride by these hydroxyl groups is quantitative.

\section{-Synthesis of regular copolyesters}

In order to control the distribution of PCL and BHET units along the polymer chain, a regular copolyester $\left(P_{1}\right)$ has been synthesized by condensation between the carboxytelechelic PCL oligomers $\underline{\mathbf{2}}$ and BHET $\underline{\mathbf{3}}$ (Scheme 2).

Figures 2 and 3 respectively show the ${ }^{1} \mathrm{H}$ NMR and ${ }^{13} \mathrm{C}$ NMR of the obtained copolyester and the assignment of all resonance signals confirming the expected incorporation of terephthalic ester units within the polycondensated chains. For instance in the ${ }^{1} \mathrm{H}$ NMR spectrum, a shift of terminal protons of BHET is observed from 3.8 to $4.4 \mathrm{ppm}$ as well as the presence of 4 protons at $2.63 \mathrm{ppm}$ assigned to the succinic ester moiety.

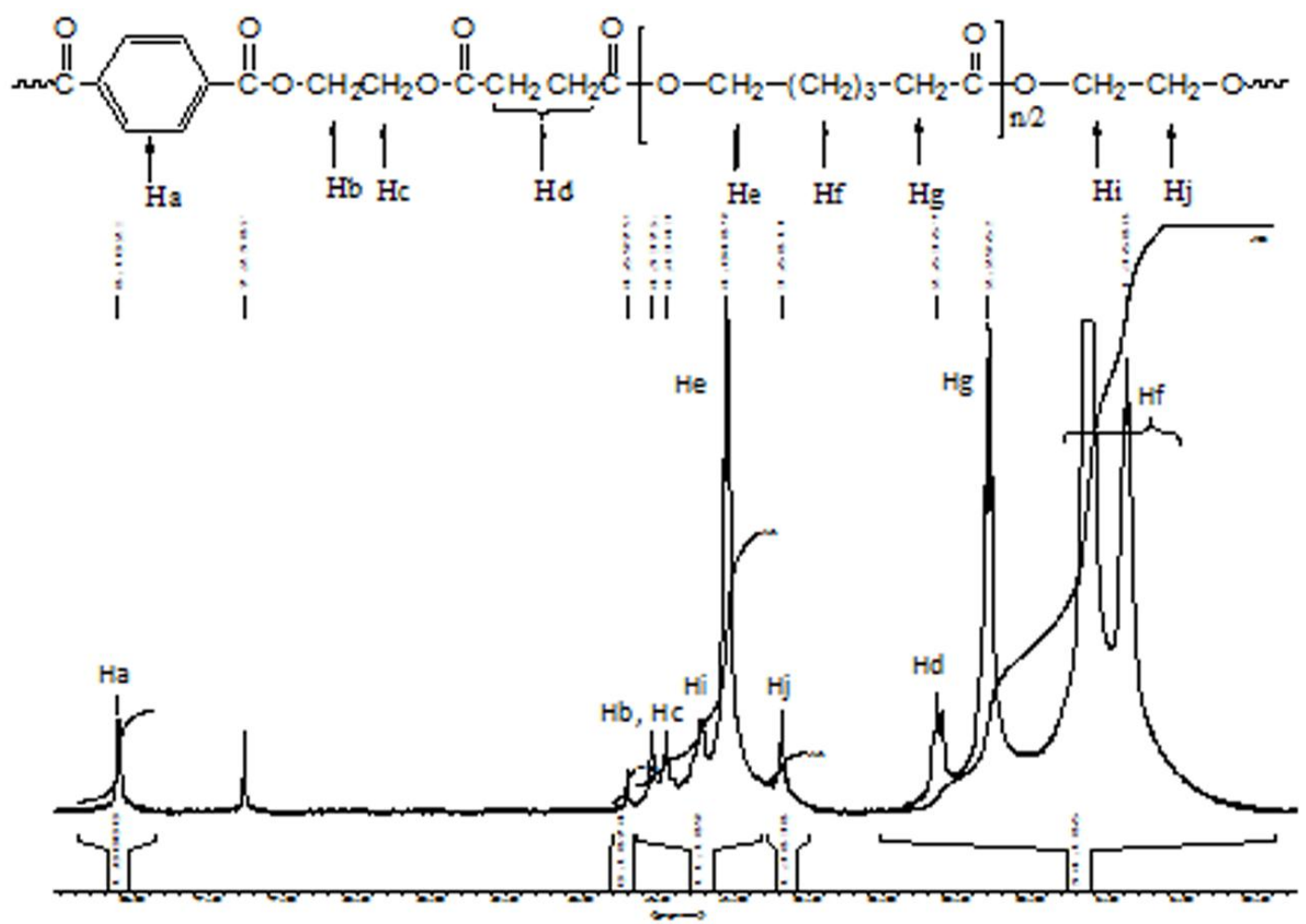

Fig. 2. ${ }^{1} \mathrm{H} \mathrm{NMR}\left(250 \mathrm{MHz}, \mathrm{CDCl}_{3}\right)$ spectrum of regular copolyester $\mathrm{P}_{1}$. 

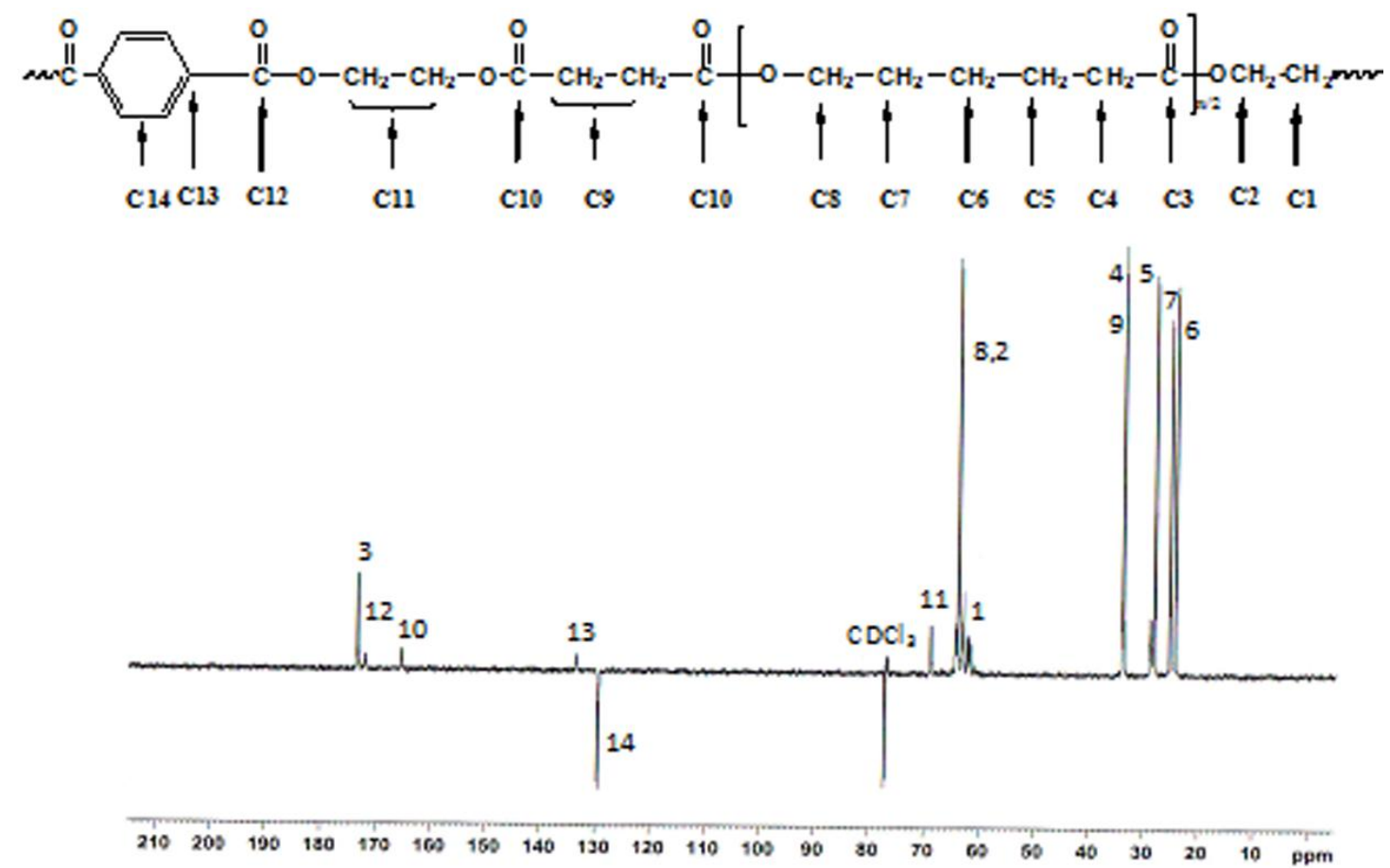

Fig. 3. ${ }^{13} \mathrm{C} \mathrm{NMR}\left(\mathrm{CDCl}_{3}\right)$ spectrum of regular copolyester $\mathrm{P}_{1}$.

From the ${ }^{1} \mathrm{H}$ NMR spectrum the composition of terephthalic ester units within the polymer chains (expressed as TU\%) could be assessed from the peak integration of aromatic protons $(8.1 \mathrm{ppm})$, and central protons of PCL segments $(3.7 \mathrm{ppm})$. The TU\% value found for $P_{1}$, using the equation (1), was $53 \%$.

$T U \%=\frac{I_{8.10}}{I_{8.10}+I_{3.70}} \times 100$

where $I_{x}$ is the peak integration value of the signal located at $x p p m$.
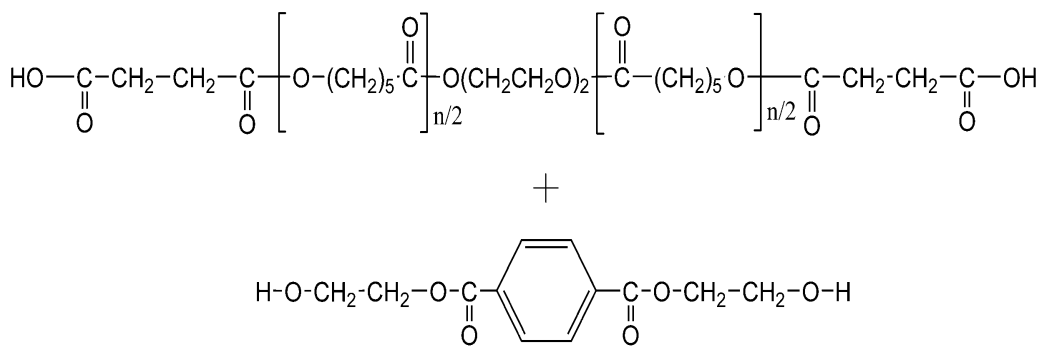

$\underline{\mathbf{3}}$

$r$

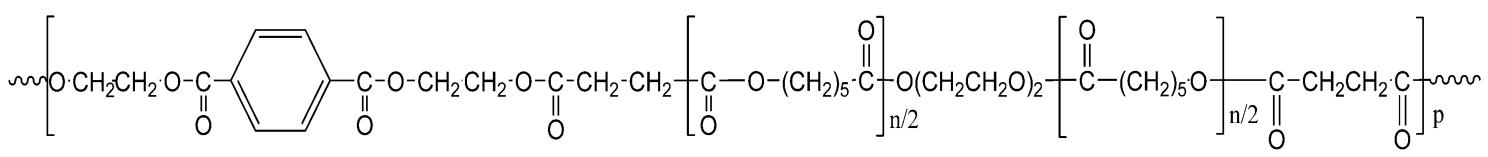

$\mathrm{P}_{1}$

Scheme 2. Synthesis of regular copolyester $P_{1}$. 
The TU\% of $P_{1}$ was also determined by UV-visible spectroscopy from the absorption intensity at $285 \mathrm{~nm}$, the obtained value was $48 \%$. This result is consistent with the theoretical and the $1 \mathrm{H}$ NMR determined values. Moreover, the number average molecular weight as determined by size exclusion chromatography (SEC), using polystyrene standards, was $29650 \mathrm{~g} \cdot \mathrm{mol}^{-1}$ with a dispersity index equal to 1.85 (Table 1). All gathered results show a good coherence and attested a successful synthesis of the regular copolyester $\mathrm{P}_{1}$.

-Synthesis of random copolyesters with different terephthalic ester contents

For the synthesis of these random polymers, the strategy illustrated in Scheme 3 has been adopted. In order to obtain polyester $\mathrm{P}_{\mathrm{i}}$ with different structures and properties, various initial molar mixtures of PCL (II), BHET (III) and succinic anhydride have been investigated.
$\mathrm{x}(\underline{\mathbf{1}})+\mathrm{y}(\underline{\mathbf{3}})+(\mathrm{x}+\mathrm{y})$<smiles>O=C1CCC(=O)O1</smiles>

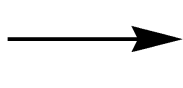
Polyesters of various properties according to values of $x$ and $y$

Scheme 3. Synthesis of random copolyester $\mathrm{P}_{\mathrm{i}}$.

The ${ }^{1} \mathrm{H}$ NMR and ${ }^{13} \mathrm{C}$ NMR spectra show several similarities to previously discussed regular copolyester $\mathrm{P}_{1}$. On ${ }^{1} \mathrm{H}$ NMR spectra, the resonance signals show up at the same chemical shifts but they differ in the values of peak integration.

Table 1 collects the initial molar ratios of reagents, composition of polyester in terephthalic units, i.e., TU\% as determined by ${ }^{1} \mathrm{H}$ NMR and UV-visible spectroscopies, and the number- and weight-average molar masses as recorded by SEC.

Tab. 1. Composition and average molar masses of different copolyesters $P_{1}-P_{6}$

\begin{tabular}{|c|c|c|c|c|c|c|c|}
\hline \multirow{2}{*}{ Polyester } & \multirow{2}{*}{ BHET/PCL/SA } & \multirow[b]{2}{*}{$(\mathrm{TU} \%)_{\text {the }}$} & \multicolumn{2}{|c|}{$(T U \%)_{\exp }$} & \multirow[b]{2}{*}{$\overline{M n}$} & \multirow{2}{*}{$\overline{M_{w}}$} & \multirow{2}{*}{$I_{p}$} \\
\hline & & & $\begin{array}{c}{ }^{1} \mathrm{H} \\
\text { NMR }\end{array}$ & $\begin{array}{c}\text { UV- } \\
\text { visible }\end{array}$ & & & \\
\hline $\mathbf{P}_{1}$ & $1 / 1 / 2$ & 50 & 53 & 48.0 & 29650 & 54900 & 1.85 \\
\hline $\mathbf{P}_{2}$ & $1 / 1 / 2$ & 50 & 48 & 47.8 & 23050 & 44050 & 1.91 \\
\hline $\mathbf{P}_{3}$ & $2 / 1 / 3$ & 67 & 60 & 68.8 & 19100 & 34450 & 1.80 \\
\hline $\mathbf{P}_{4}$ & $3 / 1 / 4$ & 75 & 79 & 71.0 & 15300 & 32700 & 2.14 \\
\hline $\mathbf{P}_{5}$ & $1 / 2 / 3$ & 33 & 33 & 29.3 & 39650 & 69400 & 1.75 \\
\hline $\mathbf{P}_{6}$ & $1 / 3 / 4$ & 25 & 20 & 22.4 & 44500 & 77450 & 1.74 \\
\hline
\end{tabular}


The values of the composition of polyesters determined by ${ }^{1} \mathrm{H}$ NMR and UV-Visible spectroscopies are consistent and show that the composition in terephthalic ester units is almost equal to the molar ratio of BHET / PCL introduced initially in the reaction mixture. Therefore, we can conclude that the introduction strategy of terephthalic ester units in the polycondensate structure is efficient and leads to copolyesters whose composition is equal to the theoretical stoichiometry.

If we compare the molecular masses of random copolyesters, we find that they decrease as their composition in TU\% increases (Table 1). $P_{6}$ is the copolyester having the lower TU\%, and presents average molecular weights three-fold higher than that of $\mathrm{P}_{4}$ having the higher TU\%. This result may be due to the high reactivity of succinic anhydride with respect to the hydroxyl end-groups of the $\alpha, \omega-\mathrm{OH}$ oligo-PCL giving carboxytelechelic PCL. Then these carboxylic groups react promptly with $\mathrm{OH}$ groups of BHET. In other words, anhydride succinic reacts better with PCL diol than with BHET. This explanation can be applied to other samples. Moreover, the molar masses become particularly important as the concentration of PCL increases, as a result of its inherent higher number-average molar weight.

Furthermore, if one compares the molar masses of $P_{1}$ and $P_{2}$, both have the same chemical composition but have been produced by two different synthesis pathways. $\mathrm{P}_{1}$ synthesized by the two-step method displays a number-average molar weight $(29650 \mathrm{~g} / \mathrm{mol})$ higher than that of $P_{2}(23050 \mathrm{~g} / \mathrm{mol})$ as obtained by the one-step approach. This result can be explained by the high reactivity of the carboxytelechelic PCL with respect to the hydroxyl groups of BHET, which strengthens our previous hypothesis. Besides, the dispersity index is close to 2 for all obtained copolyesters, characteristic value for polycondensation reactions.

\section{Thermal properties}

\section{- Analysis by Differential Scanning Calorimetry (DSC)}

Figure 4 shows the thermograms obtained during the first heating scan (see experimentals).

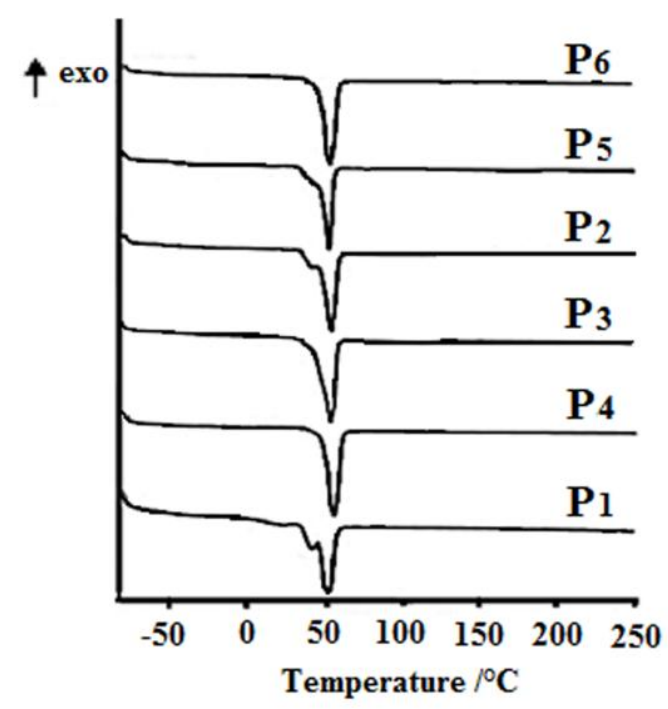

Fig. 4. DSC thermograms of different copolyesters $P_{1}-P_{6}$ as recorded during the first scan. 
There is a slight displacement of the melting peak of soft segments and glass transition temperature to higher temperatures as TU\% in copolyesters increases. This result can be explained by strong interactions between terephthalic ester units and PCL segments [25, 26].

Tab. 2. Glass transition temperature $T_{g}$, melting temperature $T_{m}$, and enthalpies of fusion $\left(\Delta H_{m}\right)$ of polyesters $\mathrm{P}_{1}-\mathrm{P}_{6}$ recorded during the first scan.

\begin{tabular}{cccc}
\hline Polyester & $T_{g}\left({ }^{\circ} \mathrm{C}\right)$ & $T_{m}\left({ }^{\circ} \mathrm{C}\right)$ & $\Delta H_{m}(\mathrm{~J} / \mathrm{g})$ \\
\hline $\mathbf{P}_{6}$ & -55.8 & 55.2 & 102.6 \\
$\mathbf{P}_{5}$ & -44.6 & 55.3 & 75.4 \\
$\mathbf{P}_{\mathbf{2}}$ & -42.3 & 55.6 & 79.3 \\
$\mathbf{P}_{\mathbf{3}}$ & -40.8 & 55.8 & 79.3 \\
$\mathbf{P}_{\mathbf{4}}$ & -37.7 & 57.2 & 86.1 \\
$\mathbf{P}_{\mathbf{1}}$ & -42.0 & 57.3 & 39.8 \\
\hline
\end{tabular}

In Table 2, we report the glass transition temperatures, melting temperatures and melting enthalpies of the investigated copolyesters as recorded during the first heating scan. There is an important decrease in melting enthalpies from $\mathrm{P}_{6}$ (TU\% equal to 25) to $P_{5}$ (TU\% equal to 33). Afterwards they increase very slightly with increasing TU\%. These results show clearly that strong interactions with terephthalic ester units prevent soft segment from crystallizing.

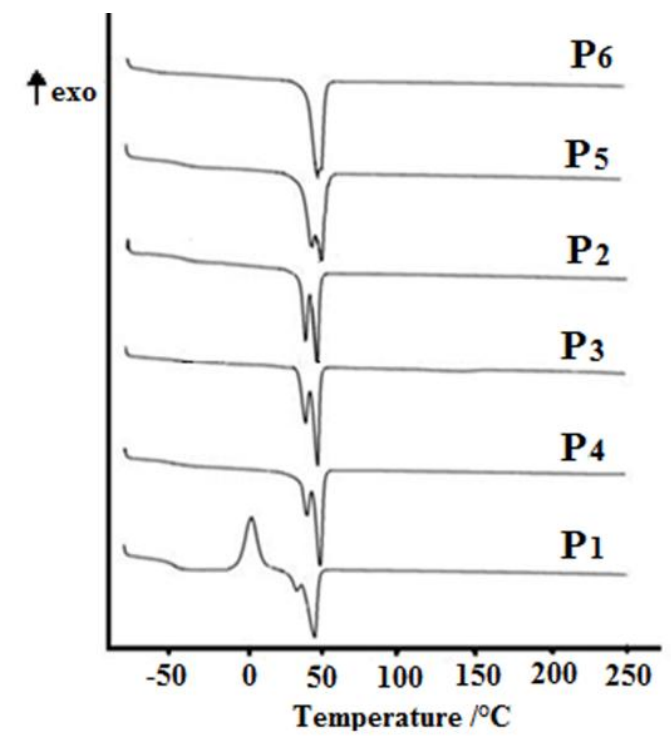

Fig. 5. DSC thermograms of different copolyesters $P_{1}-P_{6}$ as recorded during the second scan.

By comparing the thermal transitions of $\mathrm{P}_{1}$ and $\mathrm{P}_{2}$, both containing the same TU composition but differing from the synthesis method, the enthalpy of fusion of soft segments of $P_{1}$ (regular structure) is found much lower than the value recorded for $P_{2}$ 
(random structure), this is probably due to the order of arrangement of hard segments in the structural chain of regular copolyester $P_{1}$, which restricts the crystallization of soft segments, as previously discussed.

After rapid cooling, the samples underwent a second rise in temperature. The thermograms obtained (Figure 5) show the presence of two melting endotherms, indicating the presence of two distinct crystalline forms in various copolyesters that can be attributed to different degrees of arrangement or size of crystallites [16]. There are also a slight increase in glass transition temperatures and a decrease in both melting temperatures and melting enthalpies of soft segments with increasing the percentage in TU (Table 3). Such an observation more likely results from the rapid cooling of the samples, which did not have enough time to crystallize.

Tab. 3. Glass transition temperature $T_{g}$, melting temperature $T_{m}$, and enthalpies of fusion $\left(\Delta H_{m}\right)$ of polyesters $\mathrm{P}_{1}-\mathrm{P}_{6}$ recorded during the second scan.

\begin{tabular}{cccccr}
\hline Polyester & $T_{g}\left({ }^{\circ} \mathrm{C}\right)$ & $T_{c}\left({ }^{\circ} \mathrm{C}\right)$ & $T_{f}\left({ }^{\circ} \mathrm{C}\right)$ & $T f\left({ }^{\circ} \mathrm{C}\right)$ & $\Delta H_{f}(\mathrm{~J} / \mathrm{g})$ \\
\hline $\mathbf{P}_{6}$ & -53.4 & - & 47.3 & 50.7 & 70.2 \\
$\mathbf{P}_{5}$ & -44.5 & - & 44.8 & 49.0 & 61.5 \\
$\mathbf{P}_{\mathbf{2}}$ & -41.7 & - & 41.2 & 49.1 & 56.3 \\
$\mathbf{P}_{\mathbf{3}}$ & -40.2 & - & 40.3 & 48.2 & 55.0 \\
$\mathbf{P}_{\mathbf{4}}$ & -39.6 & - & 40.0 & 47.1 & 54.6 \\
$\mathbf{P}_{\mathbf{1}}$ & -40.1 & 1.5 & 41.2 & 46.0 & 41.3
\end{tabular}

The thermal behavior above described is often observed for all copolymers derived from PCL and is attributed to a more limited mobility of soft segments (or higher viscosity) when PCL is linked covalently to a polymer chain. This chemical bond between the PCL segments and other blocks restricts the phase separation and consequently the crystallization of $\mathrm{PCL}$ segments. By comparing the thermal transitions of the polyesters $P_{1}$ and $P_{2}$ containing the same composition in TU, only $\mathrm{P}_{1}$ displays the presence of an exothermic crystallization peak of PCL segments at ca. $1.5{ }^{\circ} \mathrm{C}$. Therefore, the thermal properties of the copolyesters are strongly influenced by the method of synthesis, hence the comonomer repartition along the polymer chain.

\section{-Thermogravimetric Analysis (TGA)}

The recorded TGA thermograms (Figure 6) show that all investigated copolyesters decompose through the same process. The degradation starts only around $270{ }^{\circ} \mathrm{C}$ and depends on the polyester composition in terephthalic ester units. The temperature of starting decomposition/weight loss increases with increasing the terephthalic ester units. So any increase in TU within the copolymer composition tends to endow the materials with a better thermal stability.

We can also observe that $\mathrm{P}_{4}$ is the most resistant towards thermo-oxidative degradation, due to its higher TU\%. The thermograms of copolyesters $P_{1}$ and $P_{3}$ can be superimposed, so these two copolyesters have the same thermal stability even 
though they are characterized by different structures and relative compositions. At this stage of the study no clear-cut explanation has been found out. Besides, the first stage of decomposition of the regular copolyester $P_{1}$ is shifted towards higher temperature compared to that of $\mathrm{P}_{2}$ containing the same chemical composition. This result could be explained by the fact that terephthalic ester units are distributed alternately with $\mathrm{PCL}$ segments in the copolymer chains of $\mathrm{P}_{1}$, so their influence in thermal stability is more effective.

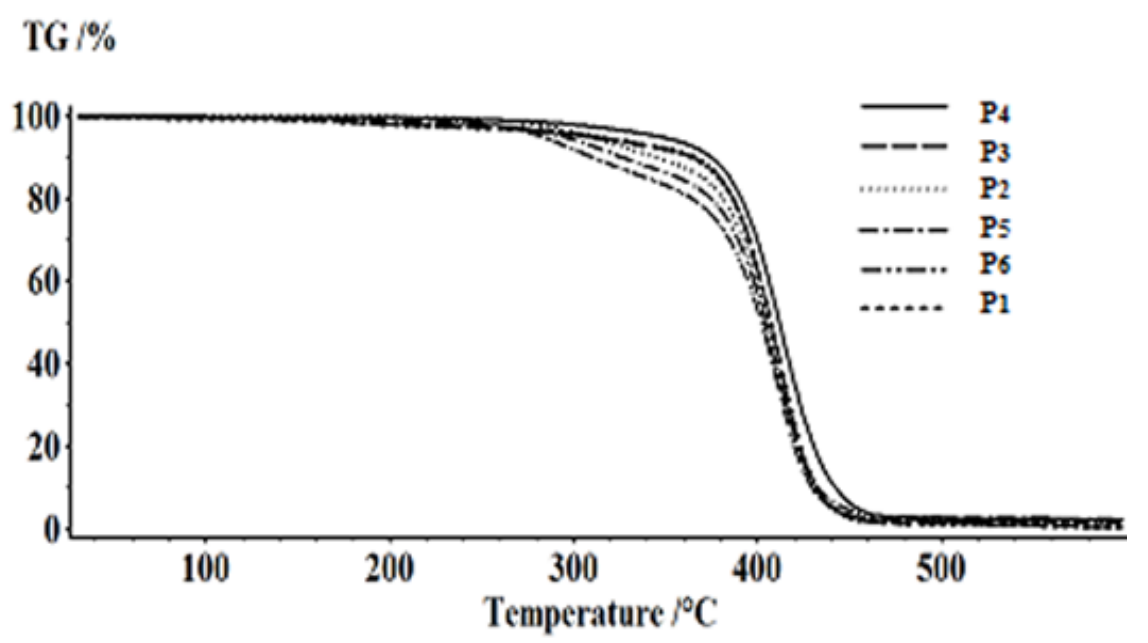

Fig. 6. TGA thermograms of copolyesters $P_{1}-P_{6}$.

\section{Conclusions}

In this work, we first mastered a simple and quantitative way to transform hydroxytelechelic PCL oligomers into carboxytelechelic PCL oligomers. This reaction was achieved by ring opening of succinic anhydride on the PCL diol. In a second step, we have also managed to introduce terephthalic units within the PCL structure according to the expected percentage and synthetic pathway. Firstly, a regular copolyester has been synthesized by direct polyesterification of carboxytelechelic PCL oligomers with BHET. Secondly, random copolyesters with various amounts of terephthalic ester units have been made available via polycondensation reaction by varying the molar ratio of $\mathrm{PCL}$ diol, BHET and succinic anhydride in the initial reaction mixture. We obtained a variety of copolyesters of variable composition ranging from $25-75 \%$ in terephthalic ester units.

The study of thermal properties by differential scanning calorimetry analysis shows that the thermal properties of the so-obtained copolyesters are influenced by the method of synthesis and relative amount of incorporated terephthalic ester units. Increasing TU\% in polyester chains improves the glass transition temperature and restricts phase separation and crystallization of PCL segments.

Thermogravimetric analysis shows that the thermal stability of polyesters strongly depends on the synthesis method and TU\%. All copolyesters decompose by the same process. The temperature of starting decomposition/weight loss increases with increasing terephthalic ester units within the polyesters. 


\section{Experimental part}

\section{Reagents}

Two poly( $\varepsilon$-caprolactone) diol ( $\alpha, \omega-\mathrm{OH}$ oligo-PCL) (number average molecular weights 530 and $2000 \mathrm{~g} / \mathrm{mol}$ ) and bis(2-hydroxyethyl) terephthalate (BHET) were purchased from Aldrich and kept in a vacuum desiccator in the presence of $\mathrm{P}_{2} \mathrm{O}_{5}$. Succinic anhydride (AS), chloroform, 1,4-dioxane, methanol, 4-dimethyl aminopyridine (DMAP) and dibutyl tin dilaurate (DBTDL) were also supplied by Aldrich. All reagents were used without further purification.

\section{Synthesis of regular copolyester P1}

-First step: Synthesis of carboxytelechelic poly( $\varepsilon$-caprolactone) oligomers

In a $500 \mathrm{~mL}$ two-necked flask equipped with a condenser, a nitrogen inlet and a magnetic stirrer, $20 \mathrm{~g}(0.01 \mathrm{~mol})$ of PCL, $2.2 \mathrm{~g}(0.022 \mathrm{~mol})$ of succinic anhydride and $1 \mathrm{~mol} \%$ of DMAP with $200 \mathrm{~mL}$ of 1,4-dioxan as solvent were introduced. The reaction occurred at $50{ }^{\circ} \mathrm{C}$. After 10 hours of reaction, the solvent was removed by evaporation under vacuum at $100{ }^{\circ} \mathrm{C}$ and the residual product was solubilized in chloroform. The reaction mixture was washed with acid water $(\mathrm{pH}=1)$ in order to remove residual succinic acid [24]. After drying on $\mathrm{Na}_{2} \mathrm{SO}_{4}$, the solvent was removed by evaporation and under vacuum at $60{ }^{\circ} \mathrm{C}$. The products were characterized by ${ }^{1} \mathrm{H}$ NMR spectroscopy and SEC.

-Second step: Copolyesterification of carboxytelechelic poly( $\varepsilon$-caprolactone) oligomers and BHET

In a $250 \mathrm{~mL}$ reactor, equipped with a mechanical agitation and a supply of nitrogen, $22 \mathrm{~g}(0.01 \mathrm{~mol})$ of carboxytelechelic poly(e-caprolactone) oligomers, $2.54 \mathrm{~g}(0.01 \mathrm{~mol})$ of BHET and 0.3 wt\% of DBTDL were introduced. The reaction mixture was heated under nitrogen at $220{ }^{\circ} \mathrm{C}$ and the pressure was set at 1000 mbar in the reactor in order to remove the formed water. After 5 hours of reaction, the reaction mixture was cooled down, solubilized in acetone and precipitated in a large excess of methanol. The obtained copolyester was dried under vacuum at $60^{\circ} \mathrm{C}$ for 72 hours.

\section{-Synthesis of random copolyester $\mathrm{Pi}$}

In a $250 \mathrm{~mL}$ reactor, equipped with a mechanical agitation and a supply of nitrogen, PCL, BHET and AS were simultaneously introduced. The mixture was heated to 100 ${ }^{\circ} \mathrm{C}$ until all products fused. The catalyst (DBTDL) was then introduced. The reaction mixture was heated under nitrogen at $220{ }^{\circ} \mathrm{C}$ and the pressure was set at $1000 \mathrm{mbar}$ in the reactor. After 5 hours of reaction, the reaction mixture was cooled down, solubilized in acetone and precipitated in a large excess of methanol. The obtained copolyesters were dried under vacuum at $60{ }^{\circ} \mathrm{C}$ for 72 hours.

\section{Techniques}

-Nuclear Magnetic Resonance (NMR)

${ }^{1} \mathrm{H}$ and ${ }^{13} \mathrm{C}$-NMR spectra were recorded on a Bruker spectrometer $250 \mathrm{MHz}$, at room temperature. The solvent used was $\mathrm{CDCl}_{3}$. Chemical shifts are given in ppm relative to TMS as an internal reference. 


\section{-UV-Visible Absorption Spectroscopy}

Measurements were carried out using an UV-Visible absorption spectrometer UVIKON 932 with double beam, deuterium and tungsten lamps. It can operate on a range of wavelengths between 190 and $900 \mathrm{~nm}$. Parallelepiped quartz cells with a length and width of $1 \mathrm{~cm}$ and a height of $5 \mathrm{~cm}$ were used. Dilute solutions $(1 \mathrm{~g} / \mathrm{L})$ in chloroform were prepared and placed in measurement cells. The measurements were carried out within a wavelength range of $200-400 \mathrm{~nm}$. The maximum absorption of BHET is at $285 \mathrm{~nm}$. The terephthalic unit percentage (TU\%) in polyesters was calculated using a calibration curve performed with solutions of different concentrations in BHET $(0.1,0.2,0.3$ and $0.4 \mathrm{~g} / \mathrm{L})$ and the absorption intensity at 285 $\mathrm{nm}$.

\section{-Size Exclusion Chromatography (SEC)}

The size exclusion chromatograms were recorded on an IOTA2 apparatus supplied by JASCO with a PU-980 Intelligent HPLC pump. The columns employed were PLgel $5 \mu \mathrm{m}$ Mixed-D 300x7.5 mm, VARIAN INC. The mobile phase was chloroform and the flow rate was $1 \mathrm{~mL} / \mathrm{min}$. Samples were injected using an injector of the Agilent 100 Series. Molar masses were determined in relation to monodisperse polystyrene standards.

\section{-Differential Scanning Calorimetry (DSC)}

DSC analyses were performed with a $204 \mathrm{~F} 1 \mathrm{NETZSCH}$. Experiments were carried out under nitrogen with samples ranging from 15 to $20 \mathrm{mg}$. The temperature range of the first heating scan was between -80 to $250{ }^{\circ} \mathrm{C}$, with a heating rate of $10 \mathrm{~K} \cdot \mathrm{min}^{-1}$, followed by a cooling at $20 \mathrm{~K} \cdot \mathrm{min}^{-1}$. A second scan was immediately performed with a heating rate of $10 \mathrm{~K} \cdot \mathrm{min}^{-1}$. Glass transition temperature was taken at the midpoint of change in heat capacity.

\section{-Thermogravimetric Analysis (TGA)}

These tests provide the mass loss of samples during heating. Measurements were performed on a TG 209 F3 NETZSCH 51. About $15 \mathrm{mg}$ of samples were put in ceramic pan and heated from 30 to $600{ }^{\circ} \mathrm{C}$ under nitrogen purge with a temperature ramp of $10 \mathrm{~K} \cdot \mathrm{min}^{-1}$.

\section{Acknowledgements}

The authors would like to thank the French-Moroccan Mixed Committee for the financial support of this work, in the framework of the project "Integrated Action $n^{\circ}$ MA/07/176". We would like to thank also the AUF for the financial project MeRSI "Ref. 6313PS006".

\section{References}

[1] Wu, C. S. J. Appl. Polym. Sci. 2004, 94, 1000.

[2] Hakkarainen, M. Adv. Polym. Sci. 2002, 157, 113.

[3] Tsuji, H.; Mizuno, A.; Ikada, Y. J. App. Polym. Sci. 1998, 70, 2259.

[4] Tokiwa, Y.; Calabia, B. P. J. Polym. Environ. 2007, 15, 259.

[5] Torres, N.; Robin, J. J.; Boutevin, B. Eur. Polym. J. 2000, 36, 2075. 
[6] Jun, H. S.; Kim, B. O.; Kim, Y. C.; Chang, H. N.; Woo, S. I. J. Environ. Polym. Degrad. 1994, 2, 9.

[7] Chiellini, E.; Corti, A.; Giovannini, A.; Narducci, P.; Pararella, M.; Solaro, R. J. Environ. Polym. Degrad . 1996, 4, 37.

[8] Laurienzo, P.; Immirzi, B.; Malinconico, M. A. Macromol. Mater. Eng. 2001, 286(4), 248.

[9] Tsai, H. B.; Kuo, W. F.; Chen, M. S.; Chang, N. S.; Chen, S. M.; Chang, S. J. J. Appl. Polym. Sci. 2003, 39, 233.

[10] Ki, H. C.; Park, O. Polymer. 2001, 42, 1849.

[11] Shaik, A.; Richter, M., Kricheldorf, H. R.; Krüger R. P. Polym. Chem. 2001, 39, 3371.

[12] Tokiwa, Y.; Suzuki ,T.; Ando, T. J. Appl. Polym. Sci. 1979, 24, 1701.

[13] Tokiwa, Y.; Suzuki ,T. J. Appl. Polym. Sci. 1981, 26, 441.

[14] Lim, K. Y.; Kim, B. C.; Yoon, K. J. J. Polym. Sci. Part B: Polym. Phys. 2002, 40, 2552.

[15] Lim, K. Y.; Kim, B. C.; Yoon, K. J. J. Appl. Polym. Sci. 2003, 88, 131.

[16] Lee, S. H.; Lim, S. W.; Lee, K. H. Polym. Int . 1999, 48, 861.

[17] Zhang, R.; Luo, X.; Ma, D. J. Appl. Polym. Sci. 2003, 55 (3), 455.

[18] Ma, D.; Zhang, G.; Huang Z.; Luo, X. J Polym Sci Part A: Polym Chem. 2000, 36, 2961.

[19] Witt, U.; Muller, R.J.; Deckwer, W.D. J. Envir. Polym. Degrad. 1997, 5(2), 81.

[20] Witt, U.; Einig, T.; Yamamoto, M.; Kleeberg, I.; Deckwer, W. D.; Muller, R. J. Chemosphere. 2001, 44(2), 289.

[21] Maafi, E. M.; Malek, F.; Tighzert, L. J. Appl. Polym. Sci. 2010, 115, 3651.

[22] Maafi, E. M.; Tighzert, L.; Malek, F. Polym. Bull. 2011, 66, 391.

[23] Maafi, E. M.; Malek, F.; Tighzert, L.; Dony, P. J. Polym Environ. 2010, 18, 638.

[24] Saint-Loup, R.; Jeanmaire, T.; Robin, J. J.; Boutevin, B. Polymer. 2003, 44(2), 3437.

[25] Li, F.; Hou, J.; Zhu, W.; Zhanc, X.; Xu, M.; Luo, X.; Ma, D.; Kim, B. J. Appl. Polym. Sci, 1996, 62, 631.

[26] Furukawa, M.; Mitsui, Y.; Fukumaru, T.; Kojio, K. Polymer. 2005, 46, 10817. 